\title{
MUNDIALIZAÇÃO DA CIÊNCIA E RESPOSTAS LOCAIS: SOBRE A INSTITUCIONALIZAÇÃO DAS CIÊNCIAS NATURAIS NO BRASIL (DE FINS DO SÉCULO XVIII À TRANSIÇÃO AO SÉCULO XX)
}

\author{
Silvia F. de M. Figueirôa \\ Depto. de Geociências Aplicadas ao Ensino - Instituto de Geociências \\ UNICAMP. C. P. 6152 - 13081-970 - Campinas - SP (Brasil)
}

\section{RESUMEN}

Se efectúa un balance de las interpretaciones dadas por la historiografía al proceso de institucionalización de las ciencias naturales en el Brasil ochocentista. Tras exponer las principales líneas analíticas que ha habido sobre las características de ese proceso se ofrece una nueva visión de cómo arraigó el cultivo de esas ciencias en la sociedad brasileña del siglo XIX. Para ello se presentan las más relevantes aportaciones empíricas y los ejes de reflexión de un conjunto de investigaciones recientes.

\section{SUMMARY}

A critical state of the art on historiography's interpretation of the Brazilian Natural Science's institutionalization process during the Nineteenth century is presented in this paper. Once dealt with the main approaches, features and interpretations made on such process a new position focused on the way those sciences were performed in the Brazilian society during the Nineteenth century is offered. In order to enlighten this new approach the main empirical contributions and the major features of a series of recent researches are presented.

\section{INTRODUÇÃO: UM MAPEAMENTO DO TEMA}

Até há pouco menos de duas décadas, as interpretações do processo de institucionalização das ciências naturais no Brasil, disseminadas pela então ainda restrita historiografia especializada, veiculavam a tese central da quase inexistência - e do grande atraso -, das atividades científicas no país até, pelo menos, a criação dos institutos de pesquisa microbiológica [a saber, Bacteriológico (1892), Manguinhos (1899), Butantan (1901) e Pasteur (1903)] na transição para o século XX. Como decorrência, esses estudos classificaram de exceção as manifestações científicas que, ainda assim, devido a alguns trabalhos de cunho sobretudo memorialista, teimavam 
em se destacar de tal passado predominantemente livresco. Além disso, a essas exceções, se se tratava de brasileiros, foi atribuído caráter ornamental e diletante, quando não de genialidade particular ${ }^{1}$, coerentemente com a tese central. A maior parte da produção mencionada foi aquela de naturalistas estrangeiros, freqüentemente homenageados com a alcunha de "Pai" de algum campo científico'. Muito dessa historiografia, em larga medida produzida por não-historiadores, padeceu dos limites dados por sua matriz positivista e pelo "mimetismo historiográfico"3 e conduziu a uma visão estreita do passado, não tendo dado conta de uma prática científica concreta que, embora tivesse existência material nos arquivos, bibliotecas e museus, não podia e não conseguia, dessa forma, encontrar seu lugar.

A formulação mais completa e teoricamente consistente desse quadro de referência - muito embora apoiada em vertentes outras que não o Positivismo -, deve-se ao trabalho seminal do cientista social e intelectual de amplos interesses e motivações que foi Fernando de Azevedo (1894-1974). Seu livro "A Cultura Brasileira" (1943) resultou de convite para escrever a introdução ao recenceamento de 1940 e nele o autor dedica um capítulo inteiro à cultura científica. Conforme analisa Motoyama, "o que há de inovador ... são as tentativas no sentido de vincular a prática científica às condições produtivas do país, à educação, à política e à religião, isto é, às condições gerais do seu desenvolvimento cultural. A insuficiente maturidade da área científica é atribuída a uma atitude de descaso e ao caráter bacharelesco e retórico da elite intelectual brasileira, que preferiu sempre belos discursos vazios, em detrimento do experimento e da prática inerentes à ciência" 4 . Nas palavras claras do próprio autor, "no mundo intelectual brasileiro em que se praticavam as letras, sem o complemento e o contrapeso das ciências, o romantismo [no século XIX] (...) tinha de forçosamente acentuar a velha tendência colonial à literatura e ao subjetivismo, arrebatando todos os seus valores e devastando tudo à sua passagem como uma torrente de montanha" 5 .

Alguns anos mais tarde, em 1955, o tema da cultura científica foi retomado no livro "As ciências no Brasil", obra em dois volumes coordenada por Azevedo e na

1 Ver, a respeito, as referências ao matemático "Souzinha" (Joaquim Gomes de Souza, 1829-1864), ou ao artista e inventor franco-brasileiro Hercules Florence (1804-1879), considerado um "inventor no exílio" (cf.: KossoY, B., (1976), Hercules Florence. 1833: a descoberta isolada da fotografia no Brasil, Ed. Duas Cidades, São Paulo; CARElli, M., (1994), Culturas cruzadas. Intercâmbios culturais entre França e Brasil, Ed. Papirus, Campinas)

2 P. ex., o engenheiro alemão Wilhelm-Ludwig von Eschwege (1777-1855) foi considerado por Leinz (1955) o "pai" da Geologia brasileira, assim como o dinamarquês Peter Wilhelm Lund (18011880) recebeu de Mendes (1981) igual título para o caso da Paleontologia.

3 Sobre a persistência de visões essencialmente eurocêntricas e inadequadas para pensar a realidade técnico-científica da América Latina, ver o artigo de síntese de SALDAÑA (1993).

4 Motoyama (1988), p. 176-7.

5 AZEVEDo (1943), p. 225. 
qual colaboraram "duas gerações de cientistas que, por gosto e aptidão, cultivavam nas suas horas de lazer as pesquisas históricas de suas disciplinas" 6 . Envolvido que estava numa campanha em favor do ensino público e não religioso ${ }^{7}$, a crítica de Azevedo à educação "letrada", identificada com o ensino católico, o levou a aprofundar sua análise de inspiração weberiana e a afirmar que o atraso científico brasileiro devia-se "à associação do poder civil e do religioso, caracterizado pela ContraReforma, na metrópole portuguesa, impondo a sua colônia uma deliberada política cultural obscurantista, necessária à explotação econômica" 8 , além de relacionar a institucionalização das ciências a surtos de industrialização (1914-1920 e 1939 1945) e ao crescimento da urbanização.

Assim, para Fernando de Azevedo "foi tão pequena e, salvo exceções, tão mesquinha em tão largo período, a participação do país na corrente de pensamento científico que se teve, em certa época, por sinal de inferioridade, o atraso nacional no campo das ciências fisicas e experimentais $e$, de modo geral, nas ciências $e$, se não chegou a passar em julgado a inaptidão do brasileiro para os estudos científicos, certamente se manteve por muito tempo uma atitude de ceticismo em face de perspectivas de progresso nesse vasto setor cultural"9.

No final dos anos de 1970, apesar de portadores de inegáveis avanços para o campo da História das ciências no Brasil, outros estudos mantiveram as linhas gerais do enfoque descrito. $\mathrm{O}$ de $\operatorname{Stepan}^{10}$, preocupado em buscar as raízes da pesquisa científica brasileira, ao estudar os Institutos Bacteriológico e Manguinhos adotou integralmente o modelo difusionista proposto por Basalla ${ }^{11}$. Atualmente já amplamente criticado e superado ${ }^{12}$, esse modelo, por sua rigidez e eurocentrismo e por estar ancorado na teoria da modernização, necessariamente inviabilizava a existência de atividades na "fase pré-científica" e salientava as atividades de cientistas estrangeiros durante a "fase colonial". Numa linha semelhante, posto que sua análise histórica apoiou-se fortemente no trabalho de Stepan, está o livro de Sant'Anna ${ }^{13}$, em que a famosa "revolta da vacina" (1904) - contrária à vacinação anti-variólica obrigatória - é identificada com forças sociais obscurantistas e reacionárias, em oposição à "clareza" do projeto modernizador do então Presidente Rodrigues Alves, que se assentava no tripé Microbiologia - Oswaldo Cruz - Instituto de Manguinhos.

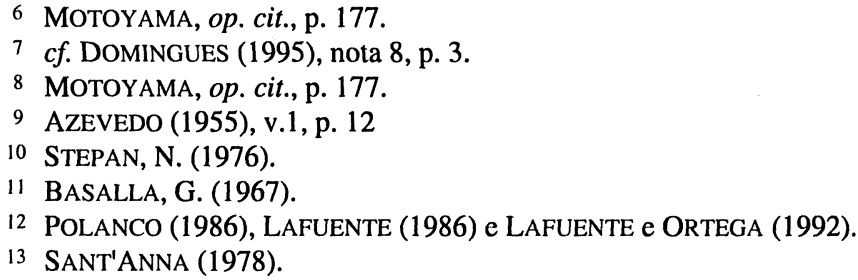




\section{SILVIA F. DE M. FIGUEIRÔA}

Por sua vez, o livro de Schwartzmann sobre a formação da comunidade científica brasileira fez coro com a visão de predominância de cientistas estrangeiros nas atividades científicas do século XIX, além de apontar extrema carência de base institucional, quando afirmou que as ciências que nessa época se faziam no Brasil eram tão somente trabalho de europeus que chegavam atraídos pelas condições oferecidas pelo Imperador e logravam, mas nem sempre, interessar brasileiros nessas atividades ${ }^{14}$. Mais ainda, esse autor conclui que o forte caráter aplicado que marcou as ciências brasileiras nesse período teria funcionado como um obstáculo ao pleno desenvolvimento científi$\mathrm{co}^{15}$, apesar de constatar que a tradição científica brasileira é "maior do que em geral se suspeita, ainda que seja menor do que muitos desejariam" 16 .

A coletânea em três volumes editada e organizada por Ferri \& Motoyama ${ }^{17}$ guarda muitas semelhanças com aquela publicada em 1955 por Fernando de Azevedo. As maiores diferenças residem na introdução de capítulos, seja dedicados a disciplinas pouco desenvolvidas ou inexistentes à epoca de Azevedo (como a pesquisa espacial), seja dedicados a campos não analisados e que mereciam investigação, como a História da Técnica e da Tecnologia, da própria História das Ciências e das instituições científicas. No entanto, também se estrutura segundo capítulos dedicados à história de diferentes disciplinas científicas, escritos majoritariamente por cientistas interessados oriundos de cada um dos campos. Além do elo de ligação direta representado por Mário Guimarães Ferri (presente em ambas), muitos autores chegaram a praticamente reproduzir o que fora escrito por seus colegas que os antecederam, fazendo pequenos acréscimos mas, essencialmente, atualizando os dados para os 25 anos que separam uma obra da outra ${ }^{18}$. Na maioria dos casos, não se escapou dos já referidos esquemas teóricos, nem do estilo de crônicas factuais.

Apesar disso, destaca-se o capítulo supra-citado sobre "Institutos de pesquisa científica no Brasil", de autoria de $\mathrm{M}^{\mathrm{a}}$ Amélia Dantes ${ }^{19}$. Considero que representa um ponto de inflexão na historiografia referente à institucionalização das ciências naturais no Brasil pelo tratamento profissional do tema, que se evidencia na preocupação em utilizar fontes primárias e originais bem como na inserção do objeto de pesquisa no contexto histórico brasileiro, ampliando os horizontes analíticos e destacando-se de uma tradição memorialista e, tantas vezes, hagiográfica. Muito embora essa possa não ter sido a intenção inicial da autora, o fato é que se abriu toda uma nova linha de investigação sobre instituições científicas e institucionalização das

14 SCHWARTZMANN (1979), p.81.

15 Idem ibidem, p. 52.

16 Idem ibidem, p. 3.

17 FERRI e MOTOYAMA (coords.) (1979-81).

18 Esse é o caso explícito, p. ex., dos textos de Josué Camargo Mendes (op. cit.) e Rui Ribeiro Franco (1981)

19 DANTES, (1980). 
MUNDIALIZAÇÃO DA CIÊNCIA E RESPOSTAS LOCAIS: SOBRE A INSTITUCIONALIZAÇÃO...

ciências no Brasil, a qual, por seu turno, se valeu grandemente de um processo de "fertilização cruzada" com a profunda renovação teórico-metodológica experimentada a partir do início dos anos 1980 pela História das ciências na América Latina ${ }^{20}$. Nesse sentido, optou-se por historiar as práticas científicas concretas que, nas instituições científicas locais, encontraram abrigo, foram por elas produzidas e, nessa dinâmica, ajudaram a produzir as próprias instituições. Abandonando a via enganosa de buscar uma grande contribuição nacional a uma ciência supostamente também grande e universal, buscou-se fazer uma "história do cotidiano" científico ${ }^{21}$ que explicitasse, sem chauvinismos, seus avanços, suas contradições, suas continuidades, rupturas e limites históricos.

\section{RASTREANDO TRAJETÓRIAS, ENCONTRANDO EIXOS}

Desde então, têm crescido numericamente os estudos preocupados com o processo de institucionalização de atividades científicas no Brasil em épocas antes consideradas pouco férteis ou dignas de menção ${ }^{22}$. Seja por meio de estudos de caso, seja por enfoques mais panorâmicos, tais pesquisas revelaram sistemática e repetidamente alguns pontos que, em minha opinião, já podem ser assumidos como fundamentos de uma nova visão.

O primeiro deles, em função da perspectiva metodológica adotada e do lastro de pesquisa empírica, é a contraposição à tese central dos estudos revistos no primeiro ítem do presente artigo. Isto é, a existência de atividades científicas no Brasil no período que se estende do final da Colônia à implantação dos institutos de pesquisa microbiológica (início da República) é expressiva, e até mesmo bem maior do que os enfoques mais otimistas esperavam encontrar ${ }^{23}$. Tal conclusão não difere do que vem sendo confirmado para o restante da América Latina em igual período histórico, e

20 Mais detalhes em Motoyama, op. cit. nota 4, e em SALDAÑA, op. cit.

21 Tomo essa feliz expressão de empréstimo de LÉRTORA (1994)

22 Sem pretender fazer uma revisão bibliográfica exaustiva, que foge aos propósitos desse número monográfico, minha intenção é analisar os trabalhos mais extensos e aprofundados que são as dissertações de mestrado e teses de doutorado, pois trazem melhor explicitados os pontos de vista e o embasamento (empírico e teórico) de suas proposições. No entanto, dada a dificuldade dos leitores para consultar esse tipo de material, listo ao final, numa "Bibliografia de Referência", artigos curtos mais facilmente acessíveis.

23 P. ex., FIGUEIRÔA (1992, p. 150), afirma: “desde o início assumi uma postura contrária às versões mais amplamente correntes na historiografia das ciências no Brasil (...). Mesmo assim, encontrei ainda mais atividades geocientíficas do que esperava a princípio". Igualmente concluiu LOPES (1993, p. 329): "Não só existiu atividade científica no Brasil no século XIX, no âmbito das Ciências Naturais, institucionalizada nas associações científicas, publicações, escolas $e$, particularmente, museus, como a quantidade, a qualidade e a continuidade de suas manifestações, expressas também pela existência de pessoas interessadas em ciências, que enviavam e coletavam, por exemplo, produtos para os museus, superaram as nossas expectativas". 
corrobora, empiricamente, a negação que Pyenson fez à idéia de um "Macondo científico" nessa parte do mundo: "Os homens modernos da América Latina estão, e estiveram, envergonhados de um passado imaginário carente de aprendizagem cientifica pura. (...) É chegada a hora de construir uma descrição, clara e completa, da ciência moderna na América Latina (...). Os resultados de tal estudo revelariam milhares de indivíduos florescendo em centros de ensino ou de investigação" 24 .

Um segundo ponto, praticamente a definir um padrão de desenvolvimento do processo de institucionalização das ciências naturais no Brasil nesse período, diz respeito ao crescimento quantitativo e à continuidade temporal dos espaços institucionais. Se no início do século XIX se contavam, basicamente, o Jardim Botânico (1808), a Academia Real Militar (1810) e o Museu Nacional (1818), a transição ao XX vai constatar, além da permanência dessas instituições já então quase centenárias (algumas reformadas e subdivididas, como foi o caso da Academia Militar, que nos anos de 1850 separou o ensino militar do civil), a multiplicação de museus regionais, escolas profissionais, associações de cientistas, comissões de serviços afeitos aos levantamentos do território e um observatório astronômico, que foram surgindo no passar do século.

E do exposto decorre um terceiro ponto: a especialização dos espaços institucionais que, se de um lado foi responsável pela multiplicação, de outro implicou sucessivas reformas nas instituições pré-existentes, as quais repassaram funções e atribuições originais, reordenando-se internamente para acompanhar o processo geral de crescente profissionalização e especialização científicas.

Um quarto ponto, de destaque posto que alicerça o processo, relaciona-se à importância do Estado, português de início e brasileiro posteriormente a 1822, na promoção das atividades científicas, por meio da criação de instituições, do financiamento dessas bem como de outras, ligadas a iniciativas de particulares, do patrocínio a estudantes-bolsistas.

Esse aspecto, já identificado no estudo pioneiro de Dantes acima referido, tem sido progressivamente melhor compreendido. Os trabalhos de Figueirôa e de Lopes ${ }^{25}$, por exemplo, mostraram como, nos extertores do antigo sistema colonial, as reformas sócio-econômicas modernizadoras empreendidas por Portugal, fundamentadas nos ideais da Ilustração, adotaram o fomentismo estatal, e a valorização das ciências naturais - sobretudo a Botânica, intimamente ligada à agricultura, à Medicina e à Química, mas também à Mineralogia e à Metalurgia - se tornou preocupação explícita do governo português. E, ao tratarem do período imperial, ambas autoras mostram a continuidade de aspectos dessa ação "ilustrada", que além da criação ou da inter-

\footnotetext{
24 PYENSON (1988), p.230-45.

25 FIGUEIRÔA (1992), op. cit;; LOPES (1993), op. cit.
} 
MUNDIALIZAÇÃO DA CIÊNCIA E RESPOSTAS LOCAIS: SOBRE A INSTITUCIONALIZAÇÃO...

ferência mais direta na reestruturação dessas instituições científicas, delas se valeram para a execução de serviços essenciais à execução de políticas governamentais.

$\mathrm{Na}$ mesma direção, a pesquisa de Domingues ${ }^{26}$ discute a institucionalização das relações entre as ciências (particularmente a Botânica) e a agricultura no Brasil como uma problemática da política de Estado que se iniciou ainda no final do período colonial. Demonstra como tal política, de características fisiocráticas, ao se manter no tempo até a época do Império, foi capaz de articular e estimular instituições científicas que se ocupavam de ciências naturais e ainda, como, já proximamente do advento da República, os ares de um movimento descentralizador se manifestaram na regionalização das atividades científicas ligadas à agricultura.

Fonseca ${ }^{27}$, por sua vez, encaminha conclusões em idêntico sentido: "a política fomentista oficial, objetivando o fomento da economia colonial e, conseqüentemente, da economia da metrópole, contribuiu para o incremento do conhecimento de recursos brasileiros, através da transplantação de algumas culturas, da criação de jardins botânicos, da promoção de pesquisas mineralógicas e do apoio ao estabelecimento de associações científicas e literárias".

Ao mesmo tempo, esse conjunto de investigações tem também identificado outros eixos comuns - contudo, nem sempre consensuais -, que, em primeiro lugar, permitem um diálogo produtivo entre os trabalhos, no que toca a metodologias, enfoques, opções teóricas, recortes disciplinares e temporais. Em segundo lugar, constituem eixos que balizam e, num certo sentido, estruturam versões mais detalhadas do processo de institucionalização que aqui se discute. E, em terceiro lugar, sinalizam linhas de investigação, ou problematizações do tema da institucionalização das ciências no Brasil, que ao serem total ou parcialmente confirmadas ou contestadas por trabalhos futuros, contribuirão para refazer e refinar as interpretações. Tais eixos, melhor discutidos a seguir, poderiam ser sintetizados como: ciência e a construção da identidade nacional; papel dos modelos institucionais estrangeiros; ausência de universidades e existência de atividades científicas; ciência "útil" e ideologia de progresso; atividade dos cientistas locais e diversidade de seus "papéis profissionais".

\section{CIÊNCIA E CONSTRUÇÃO DE UMA IDENTIDADE NACIONAL}

Temática ultimamente bastante presente, quer nos estudos que priorizam os impactos do Imperialismo e as respostas localmente engendradas, quer naqueles mais preocupados com o papel das "periferias" nos processos de mundialização das ciências, também vem aflorando com certa recorrência para o caso brasileiro que aqui se

\footnotetext{
26 DOMINGUES, op. cit.

27 FONSECA (1996).
} 


\section{SILVIA F. DE M. FIGUEIRÔA}

discute. $\mathrm{O}$ recente trabalho de Fonseca ${ }^{28}$ elegeu-o como foco primordial de sua pesquisa, na qual a autora preocupa-se com o papel do discurso científico na construção do Brasil e do México durante o período de 1770 a 1815. Valendo-se de metodologia comparativa e assumindo cultura e política enquanto instâncias que não se separam, a autora identifica, no contexto do debate sobre a inferioridade da natureza do Novo Mundo (que, nas formulações de vários teóricos como De Pauw, implicaria subordinação e tutela política), a construção de uma ciência nacional que se constituiu como resposta às "calúnias" dos europeus e como caminho de viabilidade para as nações americanas. Assim, "as idéias de ciência partilhadas por estes cientistas serão os indicadores para a aferição do processo de conscientização de uma "nacionalidade", ainda que embrionária. Procuraram, através de seus trabalhos e do exercício de suas funções, apontar a relevância dos estudos práticos sobre a natureza e sobre as potencialidades das terras americanas, $e$ a difusão de obras preconizadoras das ciência moderna. (...) Nesta medida, a ciência adquiriu uma conotação de amplitude social e política (...) e diria que a emancipação do discurso científico antecedeu à emancipação política" 29 .

Os estudos de Figueirôa e Domingues, já acima mencionados, identificam em momentos da vida do Império uma forte relação entre promoção e desenvolvimento de atividades científicas e desafios da construção do Estado nacional. Para a primeira autora, o período de 1839 a 1870 traz a marca do "esforço de construção de uma "ciência nacional" - uma clara manifestação, no domínio científico, do nativismo que se manifestou em outros campos, como na literatura, p. ex." 30 . Mais especificamente, localiza em dois espaços institucionais (Instituto Histórico e Geográfico Brasileiro (1838) e Sociedade Vellosiana (1850) ) um nítido esforço de associação entre natureza brasileira, investigações em ciências naturais e construção da nacionalidade pelo viés das concepções deterministas ${ }^{31}$.

Domingues, por sua vez, conclui de forma muito semelhante: "em meados do século XIX, as relações das ciências com a agricultura tiveram influência também no processo de formação e afirmação do Estado nacional. Nesta época, o estabelecimento da unidade política do país através da integração do seu território levou à organização de comissões científicas de exploração do interior e à incorporação das atividades de outras áreas das ciências naturais (...). Neste contexto ocorreu ainda o aparecimento de instituiçóes como o Instituto Histórico e Geográfico Brasileiro e a Sociedade Vellosiana, onde foram privilegiados aspectos das ciências que se apresentavam estreitamente associados às demandas governamentais (...) e, neste sentido, estava de acordo com a ideologia da nação que fez das riquezas naturais do país um símbolo da

\footnotetext{
28 Idem ibidem.

29 Idem ibidem, p. 3-4 e 11.

30 FIGUEIRÔA, op. cit., p. 153-54.

31 FIGUEIRÔA (1995).
} 
MUNDIALIZAÇÃO DA CIÊNCIA E RESPOSTAS LOCAIS: SOBRE A INSTITUCIONALIZAÇÃO...

sua singularidade. (...) Assim, sob a égide da ideologia nacional, as ciências naturais seriam uma espécie de instrumento para abrir os caminhos, terrestres e fluviais, e dar a conhecer as potencialidades econômicas das diversas regiões do paí" 32 .

Discordantemente, Lopes argumenta em sentido oposto, interpretando como simples mecenato o apoio oficial às ciências naturais nesse período: "Comparativamente ao periodo anterior, as ciências naturais, de modo geral, não tiveram presença marcante nesse projeto que consolidou a economia agrária, dependente e escravocrata brasileira. A "outra face da moeda" (...) que se destaca ao nosso ver, foram as iniciativas da emergente comunidade científica que disputou, com relativo sucesso, em nossa opinião, apoio político e mecenato imperial para cada uma de suas ações e de seus diferentes interesses" ${ }^{33}$.

\section{CIÊNCIA “ÚTIL" E IDEOLOGIA DO PROGRESSO}

A concepção de ciência como algo útil, de aplicação, que persiste desde a época ilustrada até os primeiros anos do século XX, é outro ponto que se destaca e se confirma nesse conjunto de trabalhos recentes ora sob análise. Ao longo do processo de sua institucionalização, as ciências naturais foram encaradas e estimuladas em função do retorno prático que trariam ao desenvolvimento econômico, a ponto de algumas instituições terem sofrido intervenção quando o governo entendeu que não atendiam a suas demandas (esse foi o caso, p. ex., da Comissão Geográfica e Geológica de São Paulo em 1905). Isso se deveu, de um lado, à adoção e longa permanência temporal dos ideais caros à Ilustração. $\mathrm{E}$, de outro, porque num certo sentido a ciência "pura" é uma invenção do século XX. Não é demais recordar que "nossos cientistas não viveram em sua prática cotidiana uma separação tão drástica como a que foi introduzida pelo Positivismo do século XIX" 34.

O trabalho de Fonseca citado acima, por exemplo, compara a ação de 4 cientistas (Manuel Arruda da Câmara (1752 (?) - 1810) e Jacinto José da Silva Quintão (1750 (?) - 1827), brasileiros, e José Antonio Alzate (1737 - 1799) e José Ignácio Bartolache (1739 - 1790), mexicanos) em seus esforços para "difundir os chamados "conhecimentos ûteis", ou seja, aqueles que beneficiavam diretamente a sociedade (...) prop[ondo] fundamentalmente a transmissão dos conhecimentos científicos em evidência, das principais invenções, das novas técnicas e dos experimentos nas diversas disciplinas científicas" 35 . A retórica de Silva Quintão, no discurso de época por

\footnotetext{
32 DOMINGUES, op. cit., p. 302-03.

33 LOPES, op. cit., p. 331.

34 LAFUENTE (1986), p. 34.

35 FONSECA, op. cit., p. 4.
} 


\section{SILVIA F. DE M. FIGUEIRÔA}

ele endereçado aos "lavradodores brasileiros", é uma eloqüente síntese desse amálgama entre ciência, Pátria e progresso:

“... porém eu animado, e esperançado nos desejos, que tenho de ser útil a vós e ao Estado, vou participar-vos as verdadeiras luzes que tenho adquirido sobre este objeto, dando-vos o método de a propagardes para que sejais útil a vós mesmos, $e$ promovais a felicidade da minha e vossa Pátria, pelos meus e da Nação inteira, e de ter eu a satisfação de ver aceito, e posto em prática o meu trabalho Patrícios Zelosos, e agradecidos às riquezas da onipotente Natureza, julgando-me ser o primeiro que com tanta individuação vos faça conhecer a cochonilha, e a sua propagação" 36 .

Domingues, por seu turno, ao enfocar a atuação de Frei Leandro do Sacramento (1774-1829), primeiro diretor do Jardim Botânico e que aí permaneceu por mais de uma década, salienta a inextricável relação entre Botânica e agricultura patente em sua obra e experimentada em sua própria vida, de homem público e de cientista reconhecido por seus pares internacionais ${ }^{37}$. Como ele mesmo atesta em 1819: "saber somente o nome das plantas não é ser botânico; o verdadeiro botânico deve saber, além disso, a parte mais dificultosa e interessante, que é conhecer as suas propriedades, usos econômicos e medicinais, saber a sua vegetação, modo de multiplicar as mais úteis, os terrenos mais convenientes para isso e o modo de os fertilizar. Não consiste pois o estudo da história natural na simples nomenclatura; mas nas observações e nas experiências para conhecer as relações, a ordem da natureza, sua economia política, e formação da Terra, as revoluções que sofreu, e enfim as utilidades que se podem tirar das produções naturais, além das conhecidas" 38 .

Domingues destaca também nesse trabalho a trajetória da Sociedade Auxiliadora da Indústria Nacional (SAIN) (1827) como evidência de que o aperfeiçoamento das ciências naturais no Brasil teve continuidade ao longo do século XIX e aliava-se ao fator "progresso" 39

Discordando de conclusão de Schwartzmann já mencionada no primeiro ítem desse artigo, Figueirôa observou que "esse aspecto pragmático tem sido algumas vezes apontado pela historiografia das ciências no Brasil como um obstáculo ao desenvolvimento científico, como se fosse um "defeito" peculiar e não se tivesse manifestado em outros países. (...) Pelo que analisei [para as ciências geológicas],

36 QUINTÃO (1813); apud FONSECA, op. cit., p. 45.

37 DOMINGUES, op. cit., p. 118, relata: "dos seus pares internacionais, ele obteve o reconhecimento pelos gêneros que criou para a flora brasileira e pelas espécies que classificou. $O$ fato ficou atestado pelos diplomas que recebeu de sócio correspondente de várias sociedades científicas internacionais, como a Academia Real de Ciências de Munique, a Horticultural de Londres, a Sociedade Real de Agricultura e Botânica de Gand e o Instituto Colombiano. E também pelas menções que recebeu, como aquela da primeira página da Flora Brasilica Meridionalis, de August de Saint-Hilaire".

38 SACRAMENTO (1819); apud DOMINGUES, op. cit., p. 118.

39 DOMINGUES, op. cit., p. 10. 
MUNDIALIZAÇÃO DA CIÊNCIA E RESPOSTAS LOCAIS: SOBRE A INSTITUCIONALIZAÇÃO...

penso justamente que, ao invés de obstáculo, o caráter aplicado constituiu a própria base para que a atividade científica se implantasse e se institucionalizasse" 40.

Falando mais especificamente do Museu Nacional, Lopes mostra o quanto a face aplicada das ciências naturais foi essencial ao afirmar que essa instituição "funcionou, desde seus primeiros anos até praticamente o final do século [XIX], como um órgão consultor governamental para assuntos de Geologia, mineração e recursos naturais. Daí decorreu a importância de seu laboratório de análises, das amostras de sua coleção que orientariam viagens (...). A significação dessa área de conhecimentos no Museu levou, inclusive, a que ao longo de muitos anos, seus diretores fossem escolhidos exatamente em função de seus conhecimentos químicos, mineralógicos e geológicos" ${ }^{41}$.

\section{MODELOS INSTITUCIONAIS ESTRANGEIROS}

A adoção, no Brasil e em muitos outros países, de modelos institucionais gestados em outras realidades, particularmente na européia, bem como sua diversidade, só pode ser compreendida no âmbito dos processos de mundialização da ciência européia ${ }^{42}$, de um lado, dos respectivos contextos históricos e disciplinares vigentes local e temporalmente, de outro, e das interações entre esses fatores. No caso do Brasil, em primeiro lugar, a tomada de consciência por parte da Metrópole de sua defasagem em relação ao restante da Europa além-Pirineus ensejou um projeto de modernização conservadora, para o conjunto do Reino português, cujos traços ecléticos e pragmáti$\cos ^{43}$ conduziram à importação de modelos e tradições científicas oriundas de diferentes "centros" para aplicar ou solucionar problemas também diferentes - posto que os "centros" científicos não foram únicos nem permanentes para todos os campos científicos todo o tempo ${ }^{44}$. Além disso, até bem adiantado o século XX, partilhou-se a crença numa razão universal e, mais ainda, a Europa foi tomada como modelo civilizatório a ser perseguido e alcançado ${ }^{45}$. Nesse sentido, a adoção de modelos externos europeus revelaria não a inferioridade ou a tendência imitativa locais, mas uma intenção educativa, prospectiva ${ }^{46}$, adiantando-se à própria realidade para melhor conformá-la aos padrões almejados. No entanto, a recepção desses modelos foi

40 FIGUEIRÔA (1992), op. cit., p. 155-56.

41 LOPES, op. cit., p. 333

42 cf. POLANCO (1990), op. cit.

43 cf. FALCON (1982)

44 cf. FIGUEIRÔA, op. cit., p. 154-55.

45 BARROS (1976).

46 cf. BARROS, idem ibidem; Carvalho (1988). 
um processo ativo que, à semelhança da aclimatação das plantas exóticas, também adaptou e, em alguns casos, tingiu-os com as cores locais.

Em segundo lugar, a transferência da Metrópole para sua maior colônia em 1808 implicou mudanças significativas em termos do processo de institucionalização das ciências, não apenas numericamente, mas também em termos das características intrínsecas das instituições e de seus respectivos papéis. Como demonstrado claramente por Lopes:

"Se a "Casa dos Pássaros" [1784 - ca. 1812] foi um entreposto colonial e, como tal, desempenhou especificamente seu papel (compondo o projeto maior de funcionamento dos museus portugueses da Ajuda, de Coimbra ou da Academia de Ciências), o que se transferiu e se criou no Rio de Janeiro em 1818 foi um Museu metropolitano de caráter enciclopédico e universal. (...) nos anos 1890 (...), mais do que uma continuidade da tradição naturalista do Museu Nacional, [observa-se] ruptura entre o modelo de Museu Geral, "Metropolitano", enciclopédico, e o modelo dos museus cada vez mais especializados das províncias, que se afirmaram nas últimas décadas do século, justamente em contraposição ao antigo Museu do Império" 47.

\section{AUSÊNCIA DE UNIVERSIDADES VERSUS EXISTÊNCIA DE ATIVIDADES CIENTÍFICAS}

Usualmente, a historiografia discutida no início desse artigo tendeu a associar a ausência de universidades à inexistência de atividades científicas, decorrendo a segunda necessariamente da primeira. Os estudos mais recentes aqui apresentados, contudo, têm se contraposto a essa idéia. Primeiro, levando em conta o que se fez em espaços institucionais diversificados, anteriormente desconsiderados ou vistos segundo recortes muito parciais, como a Academia Científica do Rio de Janeiro (1772 - 1779) e a Sociedade Literária do Rio de Janeiro (1786 - 1794), a Casa dos Pássaros, a SAIN ou o IHGB. Em segundo lugar, enfocando mais detalhadamente as escolas profissionais ligadas à Medicina ou às Engenharias, como a Academia Real Militar e suas sucessoras (Escola Militar (1839), Escola Central (1855) e Escola Politécnica do Rio de Janeiro (1874) ), ou ainda a Escola da Minas de Ouro Preto (1875) e a Escola Politécnica de São Paulo (1893), nas quais lecionaram e formaram-se profissionais que constituíram a comunidade científica brasileira no século passado ${ }^{48}$.

Em terceiro lugar, ao focalizar e aprofundar o olhar em instituições tradicionalmente citadas, como o Museu Nacional e o Jardim Botânico, essas pesquisas fizeram aflorar atividades educacionais próprias e relações concretas entre elas e as referidas escolas profissionais. No caso da Botânica, o mencionado Frei Leandro do Sacramento

47 LOPES, op. cit., p. 330-31

48 Ver FIGUEIRÔA, op. cit.. 
MUNDIALIZAÇÃO DA CIÊNCIA E RESPOSTAS LOCAIS: SOBRE A INSTITUCIONALIZAÇÃO...

articulava em seu curso de Botânica e Agricultura sua prática inseparavelmente científica e aplicada ${ }^{49}$, trazendo para as aulas na Academia Médico-Cirúrgica suas investigações e experiências no Passeio Público, inicialmente, e no Jardim Botânico, depois.

Lopes, por sua vez, constatou que: "o Museu Nacional desde suas origens, (...) já atuava como um centro irradiador e de apoio às atividades de ensino de Ciências Naturais, uma vez que as próprias coleções que constituíram as bases de seu acervo tratavam-se de coleções de estudo dos alunos da Escola Militar do Rio de Janeiro. Ao longo do século, o Museu não ministrou apenas aulas de História Natural e Mineralogia para a Escola Militar. O Museu compartilhou professores e cedeu salas, laboratórios, coleções e instrumentos para a Faculdade de Medicina, para as Escolas Normais da Sociedade Auxiliadora da Indústria Nacional, para os cursos isolados, como os de Química e Medicina Legal, para o Colégio Pedro II" 50.

$\mathrm{E}$, mais significativo ainda, a vinculação com a questão da existência de universidades foi recorrente ao longo do século passado, em momentos históricos distintos e em diferentes administrações da instituição, atestando esforços no sentido de fortalecimento e ampliação dos estudos superiores no país - bem como seu alcance e prováveis limitações, ao não se haverem concretizado:

"em diversas ocasiões o Museu ocupou o centro dos debates sobre a criação de cursos superiores de Ciências Naturais no Brasil. Desde o início da década de 1830, Custódio Alves Serrão planejou reformular o Museu Nacional do Rio de Janeiro, para que esse se encarregasse dos cursos de Mineralogia, Química, Física, Botânica e Zoologia que eram consideradas disciplinas acessórias na Faculdade de Medicina e na Escola Militar. De 1834 a 1851, os Ministros, o Senado e a elite científica da Corte discutiram a propriedade de se instalar uma Faculdade de Ciências Naturais no Museus, no contexto das conveniências de se criar uma Universidade no Brasil, que reunisse os cursos superiores já existentes. (...) Na década de 1870, a questão do papel educacional é retomada por Ladislau Netto que, ... argumentava sobre a importância e a necessidade de se viabilizarem cursos públicos de nível superior, voltados especificamente para as Ciências Naturais desenvolvidas pelas diferentes seções do Museu. Para o final do século essas propostas seriam abandonadas, priorizando-se os cursos livres e regulares já em funcionamento no Museu para Conferências Públicas" 51.

\section{CIENTISTAS LOCAIS E DIVERSIDADE DE PAPÉIS PROFISSIONAIS}

Para finalizar, é oportuno fazer a ressalva de que, embora o papel do Estado tenha sido destacado e reconhecido como essencial, esse não deve ser encarado como um

49 DOMINGUES, op. cit., p. 117.

50 LOPES, op. cit., p. 334.

51 Idem ibidem, p. 335. 
ator único, onipresente e onipoderoso. Os estudos recentes sobre o processo de institucionalização das ciências no Brasil que vimos apresentando têm indicado que alguns espaços institucionais, como por exemplo a Comissão Geológica do Brasil (1875), resultaram de iniciativas de cientistas que, interessados em conseguir sustentação para suas pesquisas e se afirmarem profissionalmente em suas carreiras, lograram covencer o governo - porque esse também se mostrava receptivo - a criar determinadas instituições ${ }^{52}$. Ao mesmo tempo, outros loci tiveram sua origem determinada pelo desejo da própria comunidade científica da época de abrir espaço específico para a ciência que produziam ${ }^{53}$.

Da análise desse processo de construção científica, é impossível desvincular trajetórias humanas e institucionais. Exemplificando no caso do Museu Nacional, como diz Lopes: "os diretores do Museu se profissionalizavam e, nesse sentido, a própria história do Museu é também a da profissionalização científica nos diferentes ramos das Ciências Naturais, no bojo de sua institucionalização. (...) enfrentando toda a sorte de dificuldades levaram à frente suas missões, confundindo suas vidas e seus interesses pessoais e científicos com os das instituições que dirigiram, em geral por 10, 20 [anos] ou mais tempo ainda" 54 .

Tais comentários nos remetem a dois aspectos importantes. Primeiramente, confirmando análises de Lafuente e Sala ${ }^{55}$, quanto às enormes dificuldades, em situações coloniais e pós-coloniais, de se falar de cientistas profissionais, dada a fluidez dos limites entre as distintas funções sociais desempenhadas pelos intelectuais. Além disso, a figura do profissional especializado somente começou a emergir ao final do século XIX, quando a própria ciência e o cientista, mundialmente, também se especializavam. Some-se ainda a dimensão extremamente reduzida da própria elite, "uma ilha de letrados num mar de analfabetos" 56 .

Assim, os cientistas que atuaram no Brasil, de igual modo que no restante da América Latina, foram ao mesmo tempo religiosos, funcionários públicos, diretores de repartições públicas, militares, membros de associações diversas, escritores e até literatos.

Em segundo lugar, evidencia-se a inadequação das abordagens já aqui criticadas, que tenderam sempre a supervalorizar as iniciativas vindas de fora, desprezando ou desconsiderando a priori o contexto local. A institucionalização das ciências naturais no Brasil não teria ocorrido sem a participação das elites locais, que importaram modelos do exterior ao mesmo tempo em que procuraram adaptá-los e desenvolvê-los em consonância com a realidade nacional - existente ou que se almejava construir.

\footnotetext{
52 FIGUEIRÔA, op. cit., p. 151.

53 Idem ibidem, p. 151-52.

54 LOPES, op. cit., p. 332.

55 LAFUENTE e SALA (1989).

56 Carvalho (1980), p. 51.
} 
MUNDIALIZAÇÃO DA CIÊNCIA E RESPOSTAS LOCAIS: SOBRE A INSTITUCIONALIZAÇÃO...

\section{CONSIDERAÇÕES FINAIS}

Resta ainda muito por fazer nessa temática. Sem dúvida, ampliar o universo das pesquisas, por meio de estudos de caso de outras instituições ou de novos recortes temáticos e problematizações que propiciem uma visão ao mesmo tempo mais abrangente e mais precisa do processo de institucionalização das ciências naturais no Brasil. Um ponto que permanece em aberto, por exemplo, diz respeito à periodização. Dadas suas especificidades, evidentemente, cada um dos trabalhos aqui debatidos estabeleceu sua periodização particular, adequada e compatível com seus objetos de investigação. Há somente um artigo de Dantes ${ }^{57}$ a propôr uma subdivisão geral, a saber: a fase do "Iluminismo e da tradição naturalista" (fins do XVIII até 1850); a fase da "Introdução da ciência experimental" (1850-1920); e a fase das "Universidades e do desenvolvimento das ciências básicas" (1930-1945). Talvez esteja próxima a possibilidade de revê-la e, se for o caso, de torná-la mais precisa.

$\mathrm{O}$ conjunto de ensaios reunidos neste número monográfico, por seu turno, em boa medida restritos a contextos nacionais, permitem estimular novas pesquisas nas lacunas e nos pontos de conflito, além dos necessários e ainda pouco freqüentes estudos comparativos. E, quem sabe, permitir que se esbocem sínteses preliminares que retratem os atritos e as confluências do processo mais geral, latino-americano, de resposta à mundialização das ciências.

\section{BIBLIOGRAFIA CONSULTADA E DE REFERÊNCIA}

AZEVEDO, F. de (1943), A cultura brasileira, Inst. Bras. Geogr. e Estatíst., Rio de Janeiro, 535 p.

Azevedo. F. (1955), As ciências no Brasil, Cia. Ed. Nacional, São Paulo, 2 vols.

BÁRros, R. S. M. de (1986), A ilustração brasileira e a idéia de universidade, EDUSP: Convívio, São Paulo.

BASALLA, G. (1967), "The spread of modern science (a 3-stage model describes the introduction of modern science into any European nation)", Science, 156, p. 611-22.

CARVAlho, J. M. de (1980), A construção da ordem: a elite política imperial, Ed. Campus, Rio de Janeiro.

CARVAlho, J. M. de (1988), Teatro de sombras: a política imperial, IUPERJ, Rio de Janeiro; Vértice, São Paulo, 196 p.

DANTES, M. A. M. (1980), "Institutos de pesquisa científica no Brasil". En: Ferri, M. G.; Motoyama, S. (coords.) (1979-81), História das ciências no Brasil, São Paulo: EPU: Ed. USP, v.2.

57. DANTES, (1988) 


\section{SILVIA F. DE M. FIGUEIRÔA}

DANTES, M. A. M. (1988), "Fases da implantação da ciência no Brasil", Quipu, México, 5 (2), 265-75

DANTES, M. A. M. (1995), "Relações científicas e tradições científicas locais: modelos institucionais no Brasil no final do século XIX", En: GoldFARB, A. M. A.; MAIA, C. (orgs.), História da ciência: o mapa do conhecimento, Edusp, São Paulo, p. 923-31.

DANTES, M. A.; LOPES, M. M.; FIGUEIRÔA, S. F. de M., "Sciences and modernization in Brazil (1870-1920)", En: PATY, M.; PETITJEAN, P.; RASChED, R. (orgs.), Traditions scientifiques et expansion européenne, Paris, Presses Universitaires de France. (no prelo)

Domingues, M. H. B. (1995), Ciência: um caso de Política (As relações entre as Ciências naturais e a Agricultura no Brasil-Império), São Paulo, Fac. Filos., Letras e Ciências Humanas/USP, tese de doutoramento.

DOMiNGUES, M. H. B. (1996), "A idéia de progresso no processo de institucionalização nacional das ciências no Brasil: a Sociedade Auxiliadora da Indústria Nacional", Asclepio, 48 (2), 149-62.

FAlCON, F. J. C. (1982), A época pombalina (política econômica e monarquia ilustrada), Ed. Ática, São Paulo.

FerRI, M. G.; Motoyama, S. (coords.) (1979-81), História das ciências no Brasil, São Paulo: EPU: Ed. USP, 3 vols.

FigueIRÔA, S. F. de M. (1987), Modernos bandeirantes: a Comissão Geográfica e Geológica de São Paulo e a exploração científica do território paulista (1886-1931), São Paulo, Fac. Filos., Letras e Ciências Humanas/USP, dissertação de mestrado.

FIGUEIRÔA, S. F. de M. (1992), "Associativismo científico no Brasil: o Instituto Histórico e Geográfico Brasileiro como espaço institucional para as ciências naturais durante o século XIX", Interciência, Caracas, 17 (3), 141-46.

FIGUEIRÔA, S. F. de M. (1992), Ciência na busca do Eldorado: a institucionalização das ciências geológicas no Brasil, 1808-1907, São Paulo, Fac. Filos., Letras e Ciências Humanas/USP, tese de doutoramento.

FIGUEIRÔA, S. F. de M. (1995), “ 'Ciência no torrão natal': a adaptação de modelos estrangeiros e a construção de uma problemática científica nacional (1840-1870)", En: GolDFARB, A. M. A.; MAIA, C. (orgs.), História da ciência: o mapa do conhecimento, Edusp, São Paulo, p. 773-84.

FonseCA, M. R. G. F. da (1995), "Ciência e identidade na América Espanhola (1780-1830)", En: GoldFARB, A. M. A.; MAIA, C. (orgs.), História da ciência: o mapa do conhecimento, Edusp, São Paulo, p. 819-36.

FONSECA, M. R. G. F. da (1996), "A única ciência é a Pátria": o discurso científico na construção do Brasil e do México (1770-1815). São Paulo, Fac. Filos., Letras e Ciências Humanas/USP, tese de doutoramento.

FrANCO, R. R. (1981), "A mineralogia e a petrologia no Brasil", En: FERRI, M. G.; MOTOYAMA, S. (coords.), História das ciências no Brasil, EPU: Edusp, São Paulo, v.3,. p.1-42.

LAFUENTE, A. (1986), “La ciencia periférica y su especialidad historiográfica”. En: SALDAÑA, J. J. (ed.), El perfil de la ciencia en América, México: Soc. Lat. Am. Hist. Ciencias y la Tecnol., p. 31-40. 


\section{MUNDIALIZAÇÃO DA CIÊNCIA E RESPOSTAS LOCAIS: SOBRE A INSTITUCIONALIZAÇÃO...}

LAFUENTE, A.; ORTEGA, M. L. (1992), "Modelos de mundialización de la ciencia", Arbor, Madrid, tomo CXLII, 93-117.

Lafuente, A.; Sala C., J. (1989), "Ciencia colonial y roles profesionales en la America Española del siglo XVIII", Quipu, México, 6 (3), 387-403.

LeInZ, V. (1955), "A geologia e a paleontologia no Brasil", En: Azevedo, F. de, As ciências no Brasil, Melhoramentos, p.243-63.

LÉRTORA M., C. A. (1994), "Reseña crítica sobre la colección "História social de la ciencia", Integración, Ciencia y Tecnologia, Colômbia, 1 (1), 111-14.

LOPES, M. M. (1992), "Brazilian museums of natural history and international exchanges in the transition to the 20 century", En: Petitjean, P. et al. (eds.), Science and empires, Kluwer Acad. Press, Holanda, p. 193-200.

LOPES, M. M. (1993), As ciências naturais e os museus no Brasil no século XIX. São Paulo, Fac. Filos., Letras e Ciências Humanas/USP, tese de doutorado.

LOPES, M. M. (1995), “As ciências dos museus: a História natural, os viajantes europeus e as diferentes concepções de museus no Brasil no século XIX". En: GoldFARB, A. M. A.; MAIA, C. (orgs.). História da ciência: o mapa do conhecimento. São Paulo: Edusp. p. 721-32.

Mendes, J. C. (1981), "A pesquisa paleontológica no Brasil”, En: FerRI, M. G.; MotoyAmA, S. (coords.), História das ciências no Brasil, EPU: Edusp, São Paulo, v.3, p.43-71.

Motoyama, S. (1988), "História da ciência no Brasil. Apontamentos para uma análise crítica", Quipu, México, vol. 5, n.2, p. 167-189.

Polanco, X. (1986), "La ciencia como ficción. Historia y contexto", En: Saldaña G., J. J. (ed.), El perfil de la ciencia en América, México, Soc. Latinoam. de Hist. Ciencias y de la Tecnol., p. 41-56.

PolAnCO, X. (1990), "Une science-monde: la mondialisation de la science européenne et la création de traditions scientifiques locales", En: POLANCO, X. (org.), Naissance et développement de la science-monde (production et reproduction des communautés scientifiques en Europe et en Amérique Latine), Paris, Ed. La Découverte: Conseil de l'Europe: UNESCO.

PYENSON, L. (1988), "Macondo científico: instituciones científicas en América Latina a princípios del siglo XX". En: SÁNCHEZ RON, J. M. (coord.) La Junta para Ampliación de Estudios $e$ Investigaciones Científicas 80 años después, Madrid: CSIC, p. 229-49.

SALDAÑA, J. J. (1993), "Nuevas tendencias en la historia de la ciencia en América Latina", Cuadernos Americanos, México, 2 (38), 69-91.

SANT'ANnA, V. (1978), Ciência e sociedade no Brasil, São Paulo; Ed. Símbolo.

Schwartzmann, S. (1979), Formação da comunidade científica no Brasil, Ed. Nacional, São Paulo; Finep, Rio de Janeiro, 481 p.

STEPAN, N. (1976), Gênese e evolução da ciência brasileira (Oswaldo Cruz e a política de investigação científica e médica), Ed. Artenova, Rio de Janeiro, 188 p. 